\title{
Research on Optimization of a Solid Filling Mining Face Layout Based on a Combined Clamped Beam Model
}

\author{
Zhi-Yong Fu $\mathbb{D}^{1},{ }^{1}$ Xu-Fei Gong $\mathbb{D}^{1},{ }^{1}$ Peng-Fei Zhang $\mathbb{D}^{1},{ }^{1}$ and Cun-Wen Wang $\mathbb{D}^{2}$ \\ ${ }^{1}$ College of Energy and Mining Engineering, Shandong University of Science and Technology, Qingdao 266590, China \\ ${ }^{2}$ Shandong Energy Group Co., Ltd., Jinan 250014, China \\ Correspondence should be addressed to Xu-Fei Gong; gong_xufei@126.com and Peng-Fei Zhang; 122787742@qq.com
}

Received 6 January 2021; Revised 7 February 2021; Accepted 23 February 2021; Published 10 March 2021

Academic Editor: Tingting Zhang

Copyright (c) 2021 Zhi-Yong Fu et al. This is an open access article distributed under the Creative Commons Attribution License, which permits unrestricted use, distribution, and reproduction in any medium, provided the original work is properly cited.

\begin{abstract}
Optimizing the mining scheme is an essential work for improving recovery efficiency of filling mining. An optimization equation of mining face width under a gangue mining condition is derived firstly. Then, analysis of the optimization equation of the mining face width is carried out based on the measure data of the F5001 mining face in the Tangshan Coal Mine. At last, the reasonable mining face width is determined combined with numerical simulation. Results show that mining face width and roof subsidence increase with the increase of unit weight and mining depth, but decrease with the increase of the elastic modulus of roof. The maximum width of the mining face is $105 \mathrm{~m}$ in Tangshan Coal Mine. When the mining width increases from 66 to $105 \mathrm{~m}$, the increasing percentage of roof subsidence is $15-18 \%$. Roof subsidence is controlled less than $30 \%$ of the mining height. The variation range of the maximum roof subsidence is small, which means the mining face width can be designed reasonably through the proposed equation.
\end{abstract}

\section{Introduction}

It has been acknowledged that the traditional mining technology can lead to serious surface subsidence, damage, and deformation of upper buildings and ecological environment problems. It also causes deformation of the rocks around the working face and leads to extensive needs of support measures such as large deformation bolt [1]. Fortunately, the development of solid filling mining technology gives a solution for this issue [2-5]. Different from the traditional mining method, filling mining uses waste gangue to fill the goaf to control the deformation and movement of the overburden strata $[6,7]$. Thus, the surface subsidence and the damage of upper buildings can be mitigated. For the solid filling mining technology, choosing a reasonable mining face width is one of the most essential issues. A reasonable mining face width can not only reduce the cost but also mitigate the ground pressure and control the surface subsidence.

At present, scholars have carried out lots of works in the area of filling mining technology. Wang et al. [8] used similar material simulation and on-site borehole detection to study the overburden failure of solid compacted mining. $\mathrm{Xu}$ et al.
[9] established a mechanical model for analyzing the relationship between the compressive modulus of the filling body and the development height of the rock beam. Yu et al. [10] analyzed the support mechanism of the filling body based on rock mechanics, control principles of the roadway, and other related theories. Liu et al. [11] studied the working performance of hydraulic support with field monitoring, numerical simulation, and theoretical analysis. Zhang et al. [12] analyzed the relationship between support of filling mining and the surrounding rock. Zhao et al. and Zhao et al. $[13,14]$ used numerical simulation and theoretical analysis to study the evolution of the abutment pressure distribution and its influence on the coal damage. Deng et al. [15] studied the roof movement characteristics under filling mining condition by establishing the elastic foundation beam model. Gong [16] studied the layout optimization of a fully mechanized mining face under specimen geological conditions.

Because the roof is supported by the filling body, the size of the mining face can be further optimized, and the filling of the mining face can be reasonably improved to reduce the cost per ton of coal. At present, there is little research on 
determining the size of the mining face under the filling and mining conditions. In this paper, we first propose the optimization equation of mining face parameters for a solid filling mining condition based on the combined beam model. Then, practical calculations are performed based on the data of the F5001 mining face in the Tangshan Coal Mine, China. At last, the reasonable mining face width is determined combined with numerical simulation.

\section{Clamped Beam Model of Goal- Roof Combination}

2.1. Basic Assumptions and Equations. Considering the geometry characteristics and engineering practice, we introduce four hypotheses of material mechanics:

(1) Plane hypothesis: the cross section of the beam still keeps planar after deformation

(2) No normal stress hypothesis of longitudinal fiber: there is no interacted normal stress among longitudinal fibers

(3) Liner elastic hypothesis

(4) Homogeneous beam hypothesis: the beam consists of homogeneous material

The overburden pressure is simplified as a uniform load. Assuming that the coal seam suffers from elastic-plastic deformation, there are two cases, one neglecting the lateral deformation of the coal seam and the other not. Then, the deformation of the coal seam in the thickness direction is analyzed. In the theoretical study of the roof deformation law, the roof is simplified as an elastic combined clamped beam.

The simplified coal seam and roof and the calculation model are given in Figure 1.

The dominant failure mode of the roof is shear failure. Thus, the roof can be simplified as a combined clamped beam, where only elastic deformation is considered. Assuming that the roof is rigid and suffers from no deformation, the clamped beam model is given in Figure 2.

The relevant variable is defined as

$$
w=\frac{\gamma L^{4}}{32 E \cdot H^{2}},
$$

where $w$ is the vertical deflection of the roof, $m ; H$ is the thickness of the roof, $m ; L$ is the equivalent elastic beam span of the roof, $m$; $E$ is the equivalent elastic modulus, MPa; and $\gamma$ is the unit weight, $\mathrm{kN} / \mathrm{m}^{3}$.

2.2. Maximum Deflection Equation of the Clamped Beam. In the combined clamped beam model, a section of the clamped beam is assumed as square. The simplified section of the roof is given in Figure 3. follows:

The calculation equation of this square section is as

$$
I_{z}=\frac{H^{4}}{12}
$$

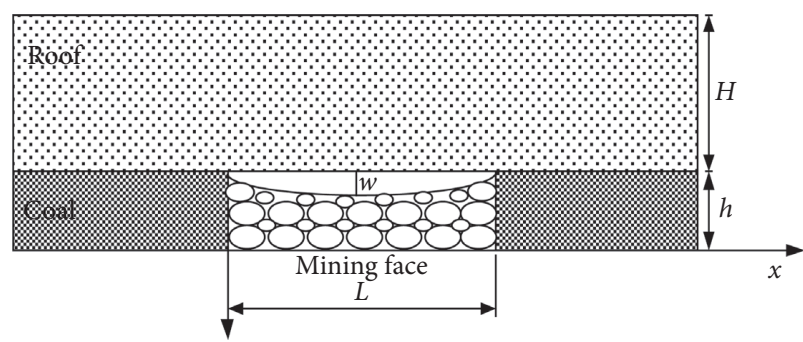

FIGURE 1: Sketch of the calculation model.

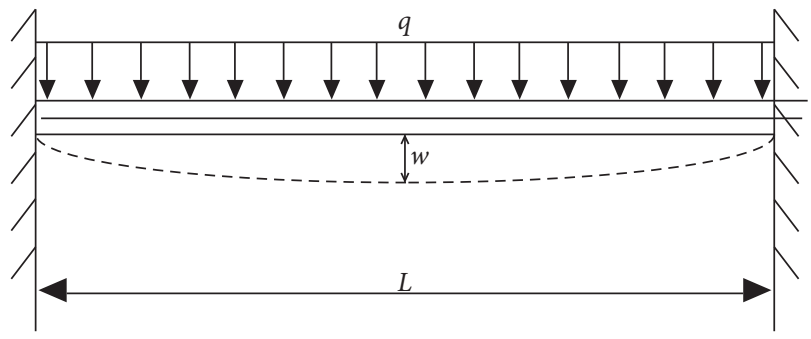

Figure 2: Sketch of the clamped beam model.

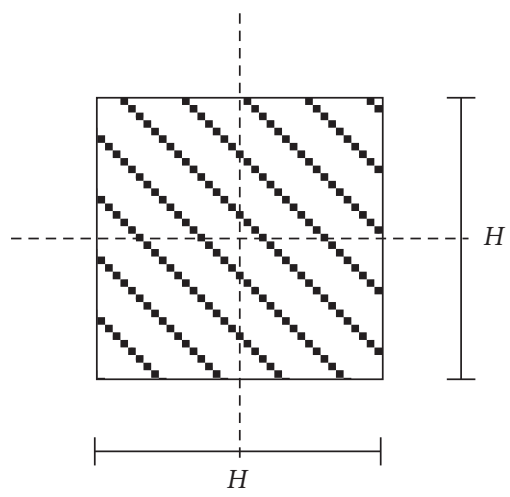

Figure 3: Sketch of the square section of the clamped beam.

The overburden rock masses of the mining face are stratified based on their physical and mechanical properties. The $H$ in Figure 4 is layered and combined to calculate its equivalent section moment of inertia. According to the combined beam theory, the $H$ in equation (2) is stratified as well. After the section is stratified, the equivalent equation of the inertia moment is as follows:

$$
I^{*}=\left\{e^{L}+e^{\left(\beta^{2}-1\right)\left(384 / 5(0.5 \alpha L)^{4}\right)\left[(1 / \cosh \cdot(\alpha L / 4))+\left((\alpha L)^{2} / 32\right)-1\right]}\right\} I,
$$

where $I^{*}$ is the equivalent inertia moment, $\mathrm{m}^{4}$; $I$ is the conventional inertia moment, $\mathrm{m}^{4} ; \alpha$ is the elastic modulus ratio of roofs in the combined beam; $\beta$, generally larger than 1 , is the ratio of $I^{*}$ and $I$; and $L$ is the span of the combined beam, $m$.

According to the equivalent inertia moment, the maximum deflection of the combined beam can be calculated with 


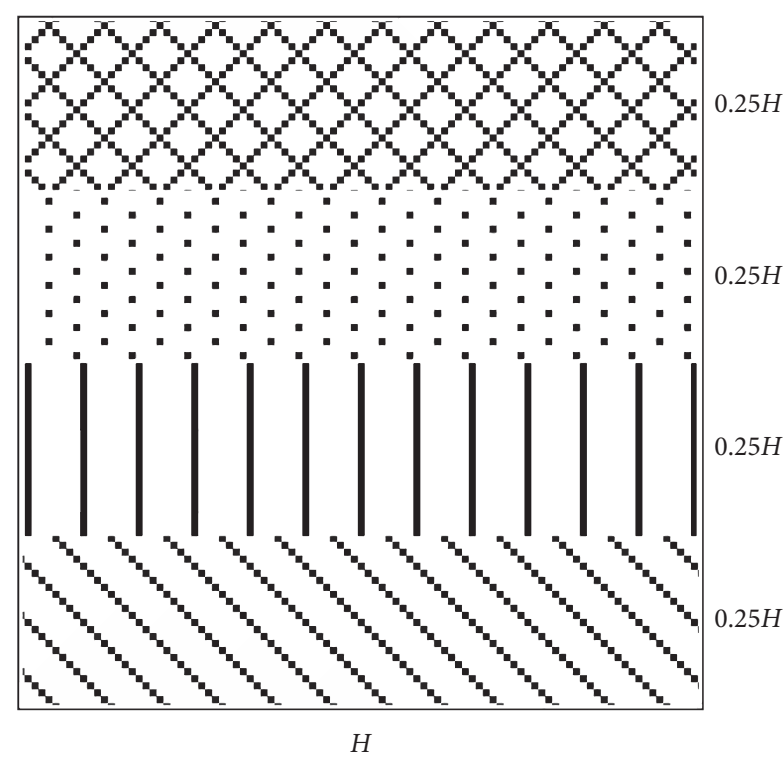

Figure 4: Sketch of the equivalent section.

$$
w=\frac{q \cdot L^{4}}{384 E \cdot I^{*}}=\frac{\gamma \cdot D \cdot L^{4}}{32 E \cdot H^{3}},
$$

where $D$ is the buried depth of the mining face, $m$.

2.3. Optimization Equation of the Mining Face. A model for obtaining the relationship between the mining face width and the tensile strength of the roof is established, which can prove a theoretical basis for the reasonable design of mining face width. Assuming that the span of a failure beam is $L$, the height $H$ and the width $b=H$. The beam is under uniform load $q$, and the neutral layer is located in the middle of the longitudinal section, as shown in Figure 5.

Taking $x>0$ as the research section, the bending moment of the rock beam is calculated with the following equation:

$$
M=\frac{q}{2}\left(\frac{L}{2}-x\right) .
$$

The tensile strength of the rock beam in the $x$-direction is

$$
\sigma_{x}=\frac{M \cdot y}{I_{z}},
$$

where $I_{\mathrm{z}}$ is the inertia moment of section in the neutral axis.

According to equations (2) and (5), the optimization equation of the mining face can be obtained:

$$
L=\frac{\sigma_{x} H^{4}}{3 y q}+2 x .
$$

The ultimate tensile strength of the goaf roof is taken as the criterion for designing the mining face width. Then, the parameter optimization of the mining face is established. According to the model of combined clamped beam, when $x$ is 0 and $y$ is $H / 2$, the tensile strength of the roof reaches the maximum. Then, the constrain condition of roof fracture is

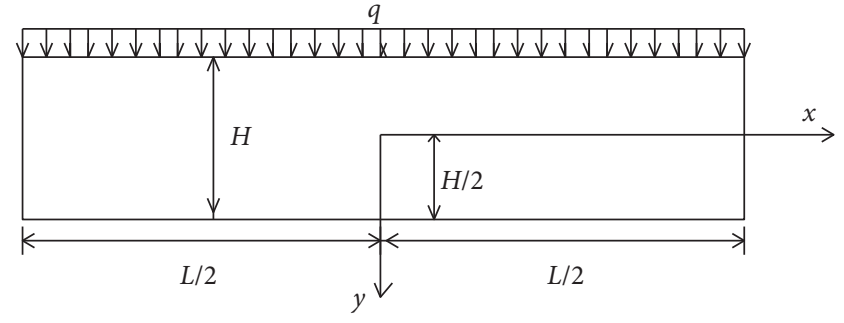

FIGURE 5: Model of the combined clamped beam.

$$
L \leq \frac{2 H^{3}\left[\sigma_{x}\right]}{3 \gamma D}
$$

\section{Analysis of Influencing Factors}

According to equation (4), calculating the maximum deflection involves a few parameters, i.e., mining face width $L$, roof subsidence $w$, roof thickness $H$, buried depth $D$, unit weight $\gamma$, and elastic modulus $E$. Elastic modulus is obtained with laboratory tests. Roof subsidence and roof thickness are obtained through field observation and theoretical analysis. Unit weight, buried depth, and elastic modulus vary greatly in different engineering conditions. Thus, the F5001 mining face of the Tangshan Coal Mine is taken as the engineering background in this paper. Then, the influences of different factors on the relationship between maximum deflection and mining face width in different conditions are analyzed using the theoretical equation.

3.1. Engineering Condition. The F5001 mining face of the Tangshan Coal Mine is in the No. 5 coal seam. The thickness varies from 1.5 to $2.3 \mathrm{~m}$ with an average of $2.2 \mathrm{~m}$. The dip angle varies from 4 to $11^{\circ}$ with an average of $7^{\circ}$. The buried depth varies from 588 to $712 \mathrm{~m}$ with an average of $650 \mathrm{~m}$. The length is $639.5 \mathrm{~m}$ in the advancing direction and $66 \mathrm{~m}$ in the inclined direction. An integrated mechanized mining method is used. The goaf is filled with waste gaugue, and the mining-filling ration is $1: 1.36$. The designed filling rate is $95 \%$ (the density of coal is $1400 \mathrm{~kg} / \mathrm{m}^{3}$, and the density of vermiculite is $1080 \mathrm{~kg} / \mathrm{m}^{3}$ ). The field borehole detection and laboratory tests show that the lithology of the roof and floor varies slightly. As shown in Figure 6, it mainly includes mudstone and sandstone. The average elastic modulus of the roof is $14 \mathrm{GPa}$.

3.2. Parameter Determination. According to equation (4), the amount of roof subsidence and the thickness of the roof can be obtained with field measurement and theoretical calculation. The roof displacement sensor in the goaf is arranged to monitor the subsidence of the roof, and the fracture of the overburden is arranged along the axial direction of the drain. The TV monitors the damage of the roof. 


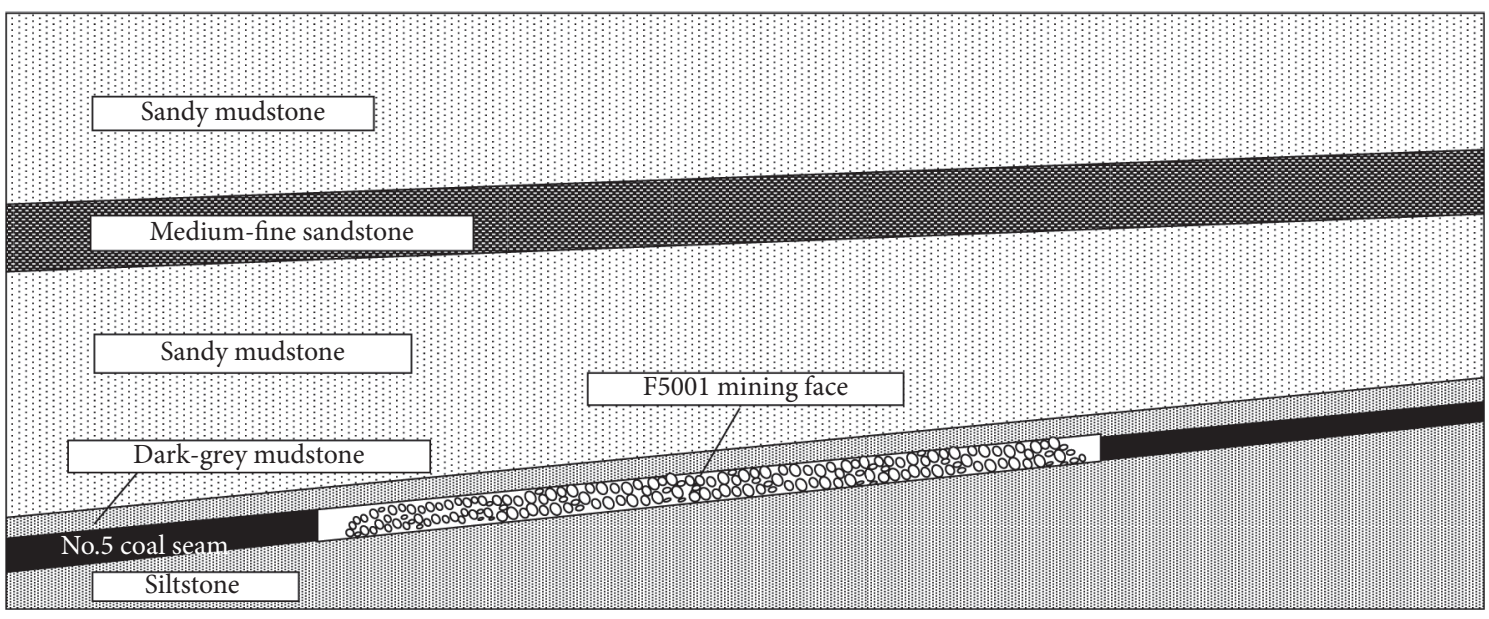

FIgURE 6: Sketch of the lithology of the roof and floor.

3.2.1. Calculation of Roof Subsidence. The maximum roof subsidence can be obtained through field monitoring. The calculation equation is

$$
H_{z}=h_{c}+h_{q}+w_{1}
$$

where $H_{\mathrm{z}}$ is the maximum roof subsidence of roof, $m ; h_{\mathrm{c}}$ is the roof subsidence before prop installation, $m ; h_{\mathrm{q}}$ is the roof subsidence from prop installation to sensor installation, and $m ; w_{1}$ is the roof subsidence monitored by the sensor, $m$.

Due to mining height and face width, there is some amount of subsidence before gangue filling, which is referred to as a roof subsidence $h_{c}$ before filling. During the filling process, easy mobility of gaugue, large filling height, etc. can lead to insufficient filling height.

The monitoring results of roof subsidence before filling are given/shown in Figure 7. The roof subsidence in the goaf is given in Figure 8. When the monitoring value keeps steady, it is $0.221 \mathrm{~m}$, which means $w_{1}$ is $0.221 \mathrm{~m}$. Before prop installation, the roof subsidence is $0.201 \mathrm{~m}$. According to the relationship between stopping distance and roof subsidence, $h_{\mathrm{q}}$ is $0.116 \mathrm{~m}$. Then, $H_{\mathrm{z}}$ is $0.538 \mathrm{~m}$.

3.2.2. Determination of Roof Thickness. According to the borehole detection, the roof separation is shown in Figure 9, and the drawing of separation distribution is illustrated in Figure 10. Within the borehole depth of 12.169-12.881 m, the roof experiences obvious separation. Thus, the average roof thickness is $12.5 \mathrm{~m}$.

3.3. Analysis of Influencing Factors. According to field monitoring results, it can be obtained that $H$ is $12.5 \mathrm{~m}, E$ is $14 \mathrm{GPa}, \gamma$ is $25 \mathrm{kN} / \mathrm{m}^{3}$, and $D$ is $650 \mathrm{~m}$. Taking these parameters into equations (3) and (4), the relationship between mining face width and deflection can be obtained:

$$
w=0.45 \cdot e^{0.003 L}+15 \times 10^{-5} \cdot e^{0.05 L} .
$$

In order to analyze the influences of different parameters on the relationship between mining face width and reflection, three analysis schemes are designed:
Scheme I (E) is $14 \mathrm{GPa},(\mathrm{H})$ is $650(\mathrm{~m})$, and $\gamma$ is $20 \mathrm{kN} /$ $\mathrm{m}^{3}, 23 \mathrm{kN} / \mathrm{m}^{3}$, and $25 \mathrm{kN} / \mathrm{m}^{3}$.

Scheme II (E) is $14 \mathrm{GPa}, \gamma$ is $25 \mathrm{kN} / \mathrm{m}^{3}$, and $(\mathrm{H})$ is $600 \mathrm{~m}, 650 \mathrm{~m}$, and $700 \mathrm{~m}$.

Scheme III $(\mathrm{H})$ is $650(\mathrm{~m}), \gamma$ is $25 \mathrm{kN} / \mathrm{m}^{3}$, and $(\mathrm{E})$ is $8 \mathrm{GPa}, 11 \mathrm{GPa}$, and $14 \mathrm{GPa}$.

According to the analysis schemes, mining face width $L$ varies from 20 to $150 \mathrm{~m}$. Influences of different factors on the mining face width are illustrated in Figures 11-13. When the mining face width face is $66 \mathrm{~m}$, roof subsidence $w$ is $0.529 \mathrm{~m}$ based on equation (10), which is very close to the field monitoring result $0.538 \mathrm{~m}$.

(1) The mining face width increases with the unit weight. When the maximum roof subsidence is $0.53 \mathrm{~m}$, the mining face width increases from 66 to $78 \mathrm{~m}$ as the unit weight increases from 20 to $25 \mathrm{kN} / \mathrm{m}^{3}$. If the mining face width is $66 \mathrm{~m}$, the roof subsidence increases from 0.51 to $0.53 \mathrm{~m}$ as the unit weight increases from 20 to $25 \mathrm{kN} / \mathrm{m}^{3}$.

(2) When the roof subsidence is steady, the mining face width increases with the buried depth. When the roof subsidence is $0.53 \mathrm{~m}$, the mining face width increases from 66 to $81 \mathrm{~m}$ as the buried depth increases from 600 to $700 \mathrm{~m}$. If the mining face width is $66 \mathrm{~m}$, the roof subsidence increases from 0.51 to $0.53 \mathrm{~m}$.

(3) When the roof subsidence is steady, the mining face width decreases with increase in the elastic modulus of roof. When the roof subsidence is $0.58 \mathrm{~mm}$, the mining face width increases from 66 to $90 \mathrm{~m}$ as the elastic modulus increases from 8 to $14 \mathrm{GPa}$. If the mining width is $66 \mathrm{~m}$, the roof subsidence decreases from 0.58 to $0.53 \mathrm{~m}$.

\section{Application of Numerical Simulation}

In order to optimize the mining scheme, equation (8) is used to determine the reasonable mining face width. Then, 


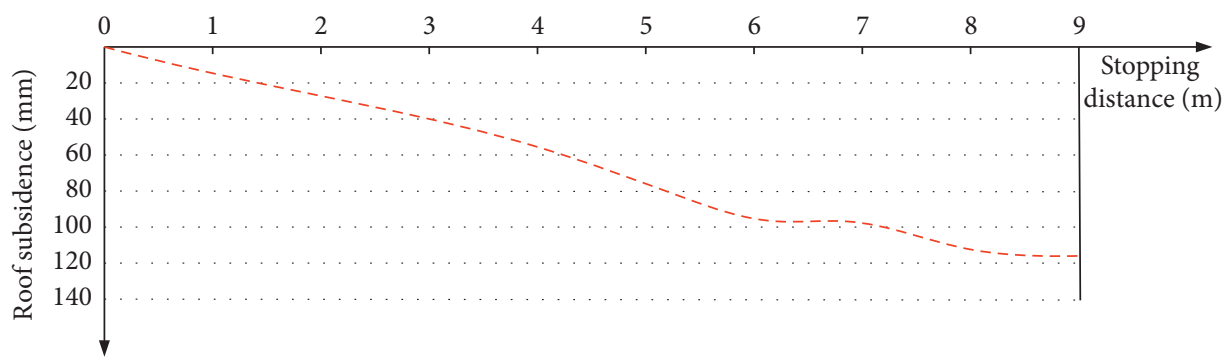

FIgURE 7: Roof subsidence before filling.

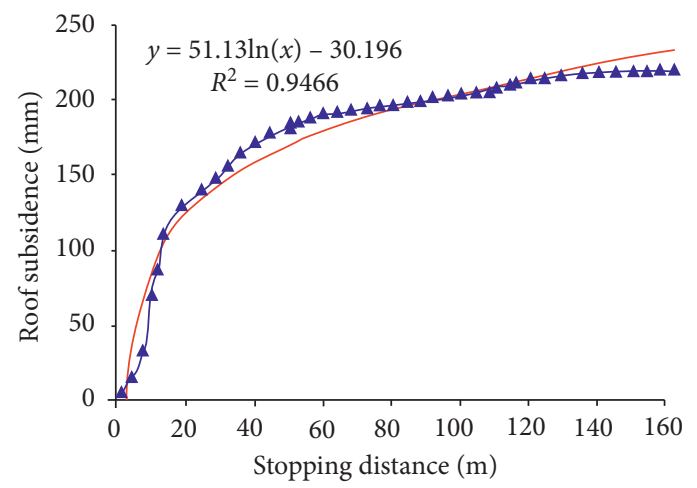

FIgURE 8: Roof subsidence in the goaf.

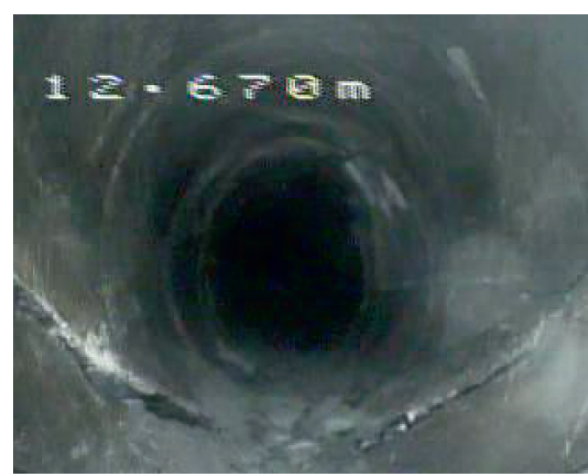

(a)

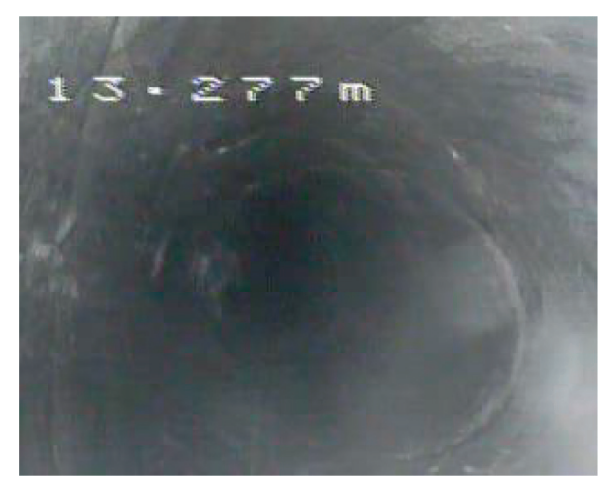

(b)

Figure 9: Separation of the roof. (a) No. 1 borehole-separation (b) No. 2 borehole-separation.

FLAC $^{3 \mathrm{D}}$ software is applied to check/testify the calculation result.

4.1. Determination of Reasonable Mining Face Width. In order to determine the maximum mining face width, $\sigma_{x}$ should be the limiting value. According to the properties of overburden strata, the limiting tensile strength is $4.72 \mathrm{MPa}$, i.e. $\sigma_{x}$ is $4.72 \mathrm{MPa}$. Then, the related mining face width is $126.3 \mathrm{~m}$ based on equation (8).

When the mining face width is $120 \mathrm{~m}$, the roof subsidence is in the range of $0.5-0.8 \mathrm{~m}$. When the mining face width is larger than $126 \mathrm{~m}$, the tensile strength of the roof reaches the maximum value $4.72 \mathrm{MPa}$. The corresponding roof subsidence is $0.83 \mathrm{~m}$, which accounts for $37.8 \%$ of mining height. Then, considering the safety coefficient 1.2 , the reasonable mining face width is $105 \mathrm{~m}$.

4.2. Numerical Model Construction. FLAC ${ }^{3 \mathrm{D}}$ is used for simulating the mining process of F5001 mining face. The actual mining face width is $66 \mathrm{~m}$, and the calculating reasonable width is $105 \mathrm{~m}$. Thus, three conditions are designed, including $66 \mathrm{~m}, 86 \mathrm{~m}$, and $105 \mathrm{~m}$. According to the engineering condition, a numerical model $(x \times y \times z=136 \mathrm{~m} \times 196 \mathrm{~m} \times 52 \mathrm{~m})$ is established, as shown in Figure 14. The strata from top to down include sandy mudstone, medium-fine sandstone, sandy mudstone, mudstone, No. 5 coal seam, siltstone, find sandstone, and 


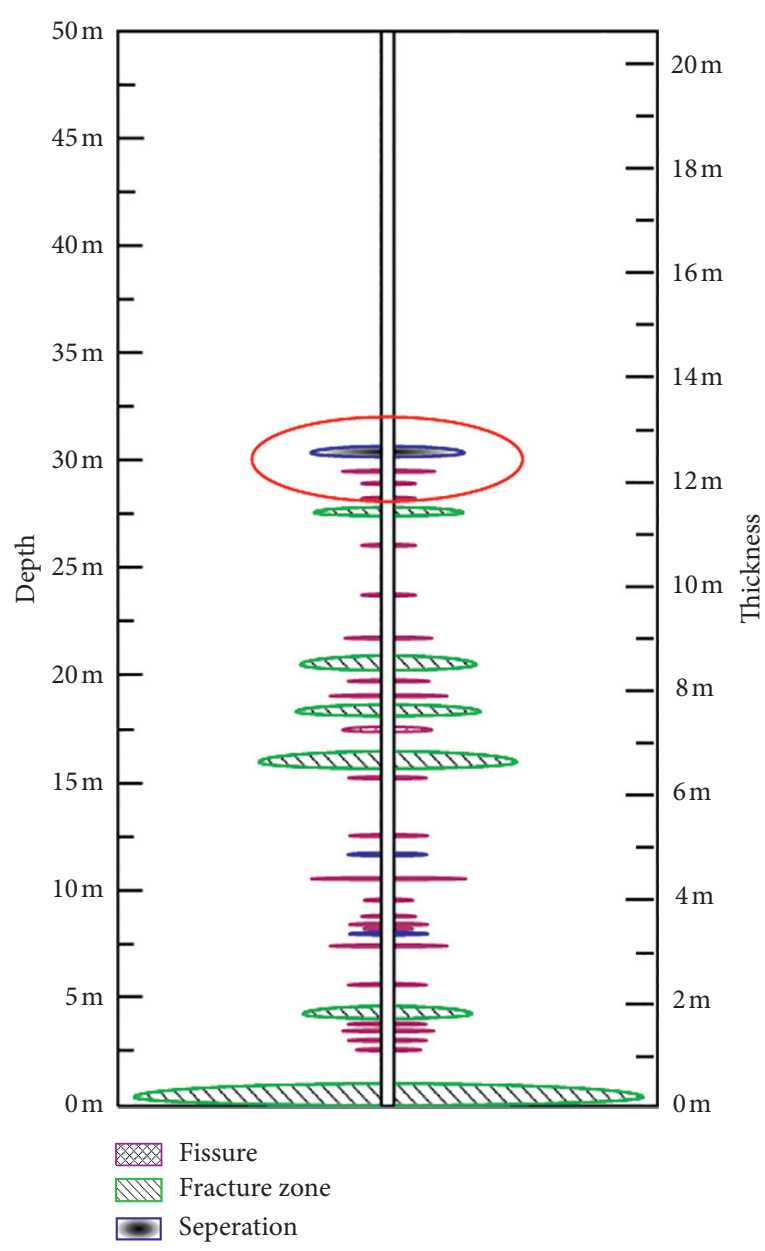

(a)

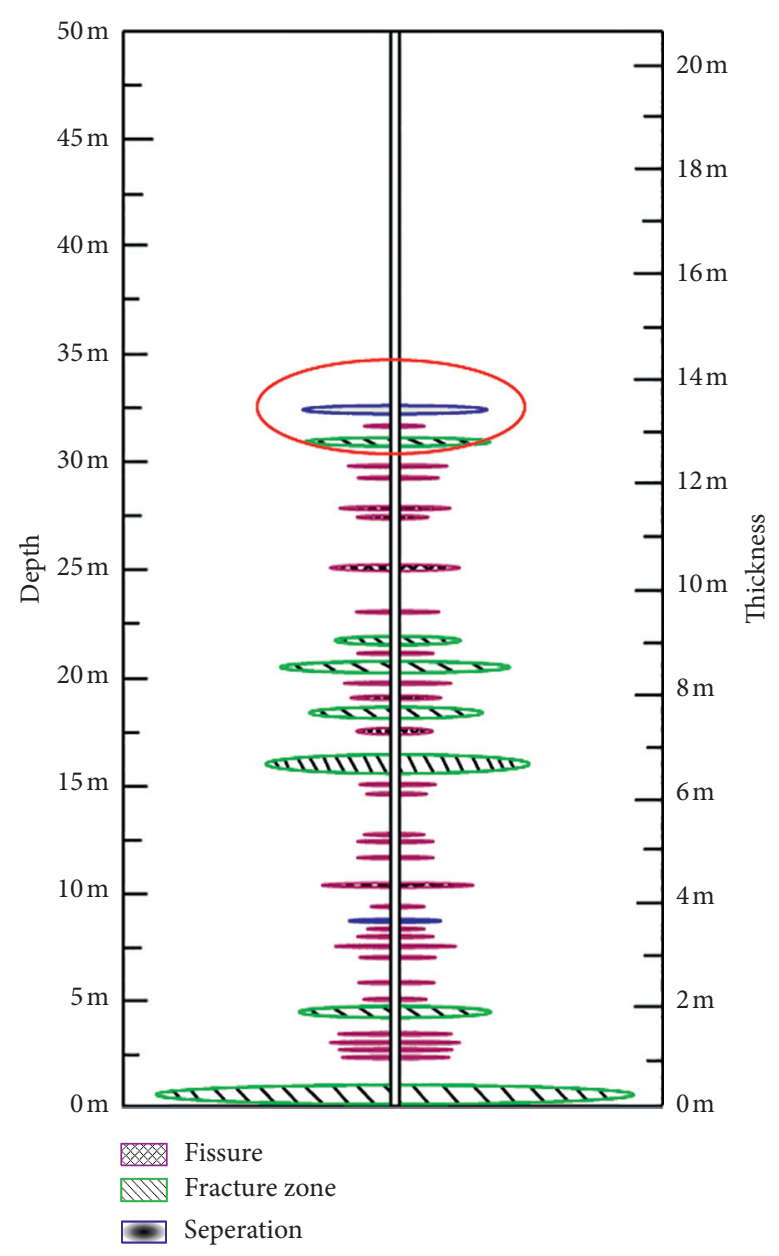

(b)

FIgURE 10: Drawing of separation distribution. (a) No. 1 borehole (b) No. 2 borehole.

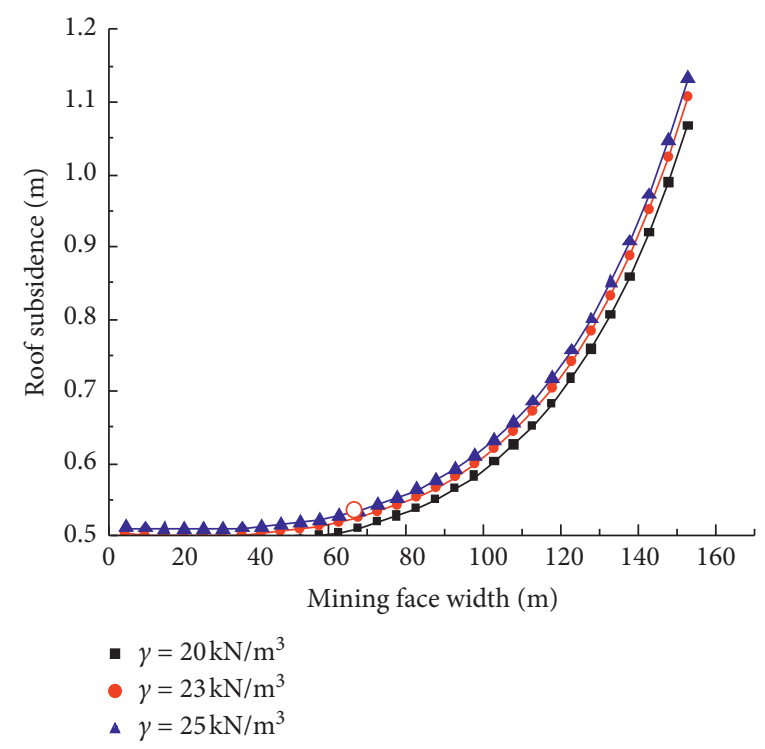

FIgURE 11: Relationship between mining face width and unit weight. 


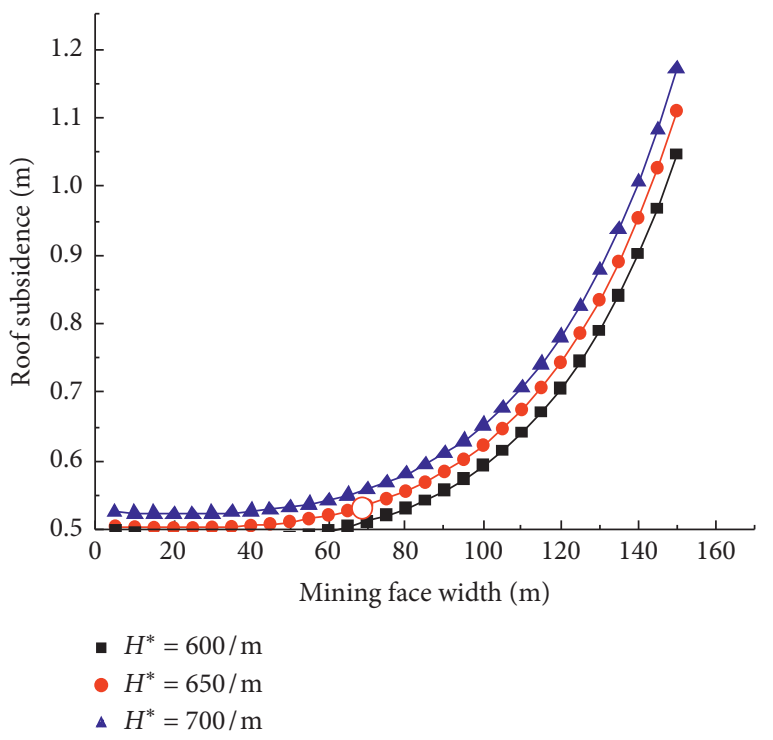

FIgURE 12: Relationship between mining face width and buried depth.

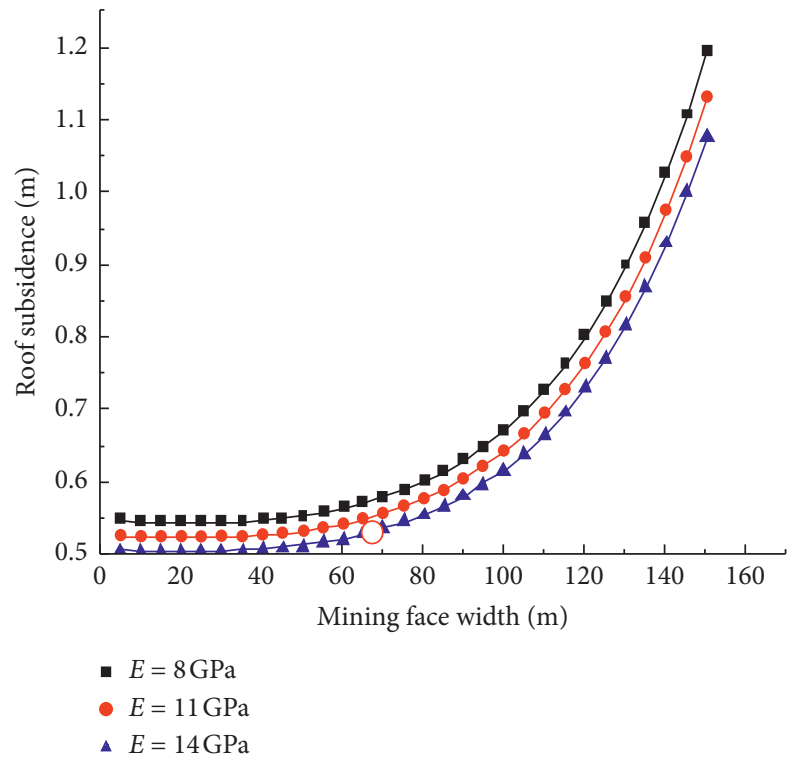

FIGURE 13: Relationship between mining face width and elastic modulus of the roof.

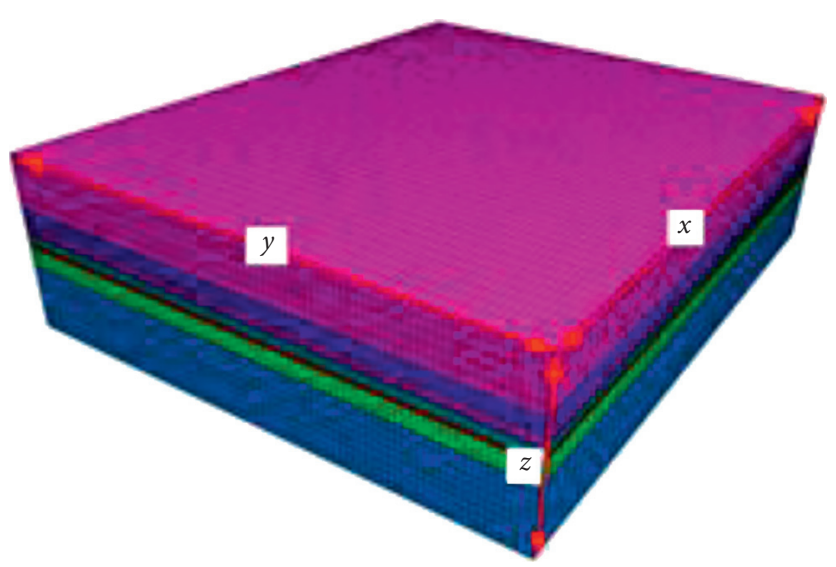

Figure 14: Numerical model. 
TABLE 1: Physical mechanical parameters of strata.

\begin{tabular}{|c|c|c|c|c|c|c|c|}
\hline Lithology & $\begin{array}{c}\text { Thickness } \\
(\mathrm{m})\end{array}$ & $\begin{array}{l}\text { Density } \\
\left(\mathrm{kg} \cdot \mathrm{m}^{3}\right)\end{array}$ & $\begin{array}{c}\text { Bulk modulus } \\
(\mathrm{GPa})\end{array}$ & $\begin{array}{l}\text { Shear modulus } \\
(\mathrm{GPa})\end{array}$ & $\begin{array}{c}\text { Internal } \\
\text { friction }\left(^{\circ}\right)\end{array}$ & $\begin{array}{c}\text { Cohesion } \\
(\mathrm{MPa})\end{array}$ & $\begin{array}{l}\text { Tensile strength } \\
(\mathrm{MPa})\end{array}$ \\
\hline Sandy mudstone & 20.5 & 2300 & 1.6 & 0.9 & 36 & 9.5 & 8 \\
\hline $\begin{array}{l}\text { Medium-fine } \\
\text { sandstone }\end{array}$ & 7.4 & 2650 & 3.31 & 1.71 & 41 & 18.5 & 14 \\
\hline Sandy mudstone & 2.0 & 2300 & 1.6 & 0.9 & 36 & 9.5 & 8 \\
\hline Mudstone & 1.3 & 2300 & 1.82 & 0.91 & 38 & 9 & 8 \\
\hline No. 5 coal seam & 2.2 & 1340 & 1.14 & 0.45 & 26 & 3 & 1.4 \\
\hline Siltstone & 1.4 & 2650 & 4.35 & 2.0 & 44 & 13 & 10 \\
\hline Fine sandstone & 5.2 & 2650 & 3.31 & 1.71 & 41 & 18.5 & 14 \\
\hline Mudstone & 20.0 & 2300 & 1.82 & 0.91 & 38 & 9 & 8 \\
\hline
\end{tabular}

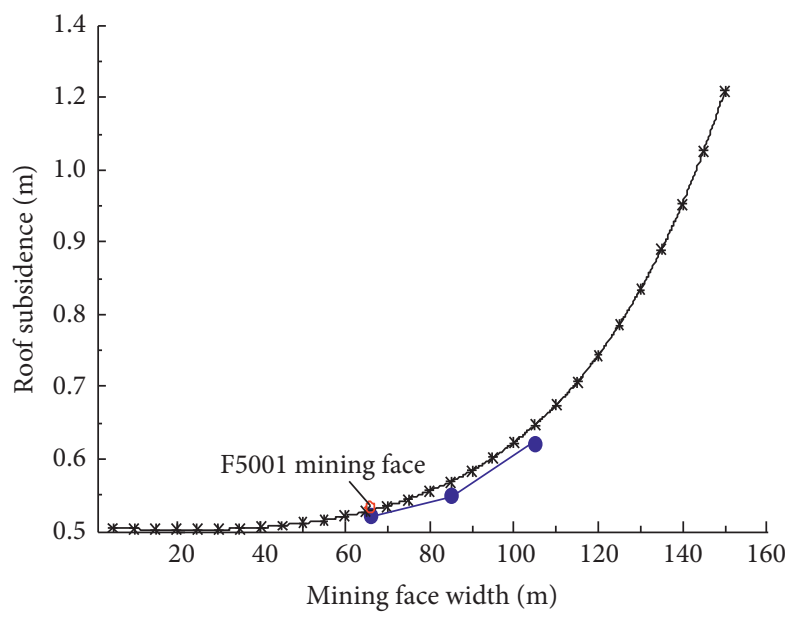

* Theoretical calculation

- Numerical simulation

- Field monitoring

Figure 15: Relationship between mining face width and roof subsidence.

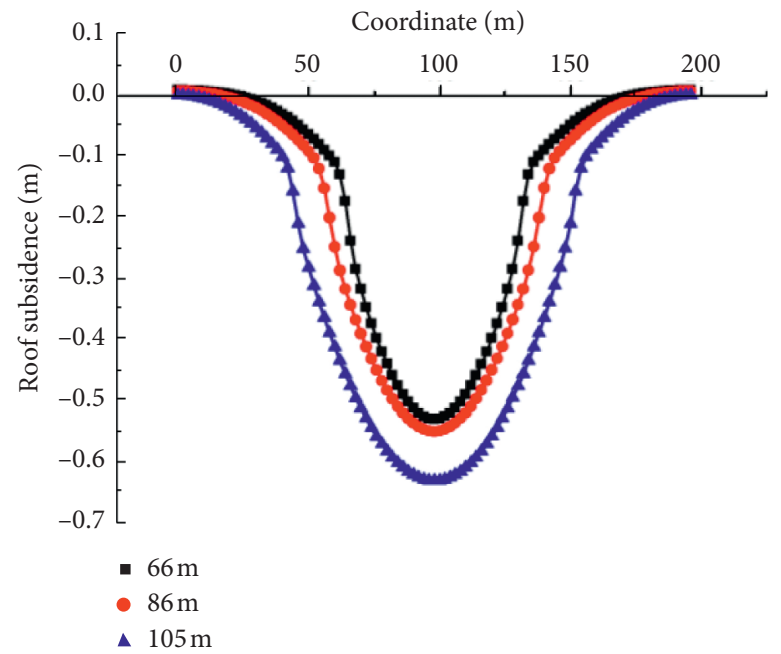

FIGURE 16: Subsidence curves with different mining face widths. 
mudstone. The Mohr-coulomb model is chosen. The physical mechanical parameters are listed in Table 1.

4.3. Analysis of Numerical Simulation Results. The Roof subsidence monitoring line is arranged in the middle of the mining face. The monitoring results are given in Figures 15-16. Additionally, theoretical calculation results are also plotted for comparison.

(1) The relationship between the mining face width and the roof subsidence can be obtained with equation (10). The numerical results show that the maximum roof subsidence is $0.524 \mathrm{~m}, 0.549 \mathrm{~m}$, and $0.623 \mathrm{~m}$, respectively. The corresponding theoretical values are $0.529 \mathrm{~m}, 0.559 \mathrm{~m}$, and $0.647 \mathrm{~m}$, respectively. The differences between numerical simulation and theoretical calculation are small.

(2) When the mining face width increases from 66 to $105 \mathrm{~m}$, the maximum roof subsidence obtained by numerical simulation and theoretical calculation increase from 0.529 to $0.647 \mathrm{~m}$ and from 0.524 to $0.623 \mathrm{~m}$, respectively. The corresponding increasing percentages are $18 \%$ and $15 \%$, respectively. Generally, the maximum roof subsidence is only $0.647 \mathrm{~m}$, accounting for $29 \%$ of the mining height. Thus, it can be concluded that when the mining face width increases to $105 \mathrm{~m}$, it is also reasonable.

\section{Conclusions}

Based on the combined clamped beam model, the roof subsidence and fracture constraint conditions used for solid filling mining are deduced. When the mining width of the F5001 mining face is $66 \mathrm{~m}$, the calculated maximum deflection of roof is very close to the field monitoring result, indicating that equation (10) is valid.

The relationship between the maximum deflection and the mining face width is obtained under different factors, i.e., unit weight, buried depth, and elastic modulus of the roof. Theoretical analysis reveals that both the maximum deflection and the mining face width increase as the unit weight or buried depth increases, but the elastic modulus of the roof decreases. When designing the sizes of mining face, these factors must be considered.

The mining face width in the Tangshan Coal Mine can be designed by the optimization equation. Combined with the field monitoring data, when the mining face width is $126 \mathrm{~m}$, the roof reaches the limiting tensile strength. The engineering safety coefficient is 1.2 , and the maximum mining face width is $105 \mathrm{~m}$.

When the mining width increases from 66 to $105 \mathrm{~m}$, theoretical calculations show that the maximum roof subsidence increases from 0.524 to $0.623 \mathrm{~m}$, whose corresponding increasing percentage is $18 \%$ while numerical simulation results show that the roof subsidence increases from 0.524 to $0.623 \mathrm{~m}$. The roof subsidence is controlled less than $30 \%$ of the mining height. Generally, when the mining width increases, the roof subsidence varies slightly under filling mining condition.

\section{Data Availability}

The data used to support the findings of this study are included within the article.

\section{Conflicts of Interest}

The authors declare that they have no conflicts of interest.

\section{Acknowledgments}

This work was supported by the Major Scientific and Technological Innovation Project of Shandong Provincial Key Research Development Program (2019SDZY01) and Shandong Provincial Natural Science Foundation (ZR2019BD063). The authors thank the Tangshan Coal Mine for their support during the field investigation.

\section{References}

[1] T. -B. Zhaon, M. -L. Xing, W. -Y. Guo, C. -W. Wang, and B. Wang, "Anchoring effect and energy-absorbing support mechanism of large deformation bolt," Journal of Central South University, vol. 28, no. 2, pp. 572-581, 2021.

[2] K. Cheng, B. G. Yang, B. G. Zhang et al., "Present situation and development direction of filling mining technology in coal mines in China," Coal Technology, vol. 37, no. 03, pp. 73-76, 2018.

[3] G. W. Liu and C. J. Yan, "Analysis of surface subsidence law of solid filling mining under buildings," Safety in Coal Mines, vol. 02, pp. 214-218, 2019.

[4] M. Li, J. X. Zhang, and Y. L. Huang, "Research on compression ratio design based on compaction properties of solid backfill materials," Journal of China Coal Society, vol. 34, no. 6, pp. 1110-1115, 2017.

[5] C. D. Sun, D. S. Zhang, and X. F. Wang, "Study and application of overlying strata control technology in bag type backfill longwall mining with super high-water content material," Journal of China Coal Society, vol. 40, no. 6, pp. 1313-1319, 2015.

[6] Z. M. Huang, Study on the Macro-Micro Mechanical Properties of Gangue Backfilling Body and Relationship between Support and Surrounding Rock in Comprehensive Mechanized Filling Mining, China University of Mining and Technology, Beijing, China, 2016.

[7] Q. Zhang, J. Zhang, Y. Huang, and F. Ju, "Backfilling technology and strata behaviors in fully mechanized coal mining working face," International Journal of Mining Science and Technology, vol. 22, no. 2, pp. 151-157, 2012.

[8] L. Wang, X. N. Zang, and G. L. Guo, "Research on surface subsidence prediction model of coal mining with solid compacted backfilling," Rock and Soil Mechanics, vol. 35, no. 7, pp. 1973-1978, 2014.

[9] P. Xu, Y. J. Zhou, and M. X. Zhang, "Fracture development of overlying strata by backfill mining under thick alluvium and thin bedrock," Journal of Mining and Safety Engineering, vol. 32, no. 4, pp. 617-622, 2015.

[10] W. J. Yu, T. Feng, and W. J. Wang, "Coordination support systems in mining with filling and mechainical behavior," Chinese Journal of Rock Mechanics and Engineering, vol. 31, pp. 2803-2813, 2012.

[11] X. M. Liu, T. B. Zhao, and M. Q. Wang, "Analysis of working characteristics and roof control of backfilling hyaraulic 
support," Journal of Shandong University of Science and Technology (Natural Science), vol. 36, no. 2, pp. 42-47, 2017.

[12] Z. N. Zhang, X. X. Miao, and X. R. Ge, "Testing study on compaction breakage of loose rock blocks," Chinese Journal of Rock Mechanics and Engineering, vol. 24, no. 3, pp. 451-455, 2005.

[13] T. B. Zhao, H. H. Zhang, and Y. J. Chen, "Evolution of abutment pressure distribution and impact on coal-rock damage," Journal of Liaoning Technical University (Natural Science), vol. 29, no. 3, pp. 420-423, 2010.

[14] T. B. Zhao, W. Y. Guo, and Y. L. Tan, "Mechanics mechanism of rock burst caused by mining in the variable region of coal thickness," Journal of China Coal Society, vol. 41, no. 7, pp. 1659-1666, 2016.

[15] X. J. Deng, J. X. Zhang, and P. Huang, "Roof movement characteristics in extra thick coal seam mining with the upward slicing filling technology," Journal of China Coal Society, vol. 40, no. 5, pp. 994-1000, 2015.

[16] P. L. Gong, Surrounding Rock Control Theory and Application Study of the Coal Face with Greater Mining Height, Taiyuan University of Technology, Taiyuan, China, 2006. 